in overdose? Acta Psychiatrica Scandinavica, 80/suppl 1354), 47-54.

MURPHY, E. (1983) The prognosis of depression in old age. British Journal of Psychiatry, 142, 111-119.

Song. F., Freemantle. N., Sheldon. T.A., House. A. et al (1993) Selective serotonin reuptake inhibitors: metaanalysis of efficacy and acceptability. British Medical Journal, s06, 683-687.
John Wattis, Consultant and Sentor Lecturer in Psychiatry for Old People, Bridge House, Balm Road, Leeds LS10 2TP; Peter Bentham, Consultant in Psychiatry for Old People, Queen Elizabeth Hospital, Birmingham, B15 2Q2; and John Bestley. Senior Registrar in Psychiatry for Old People, Yorkshire Training Scheme

\title{
Psychiatric admission services for people with learning disability
}

\author{
I. Singh, M.I. Khalid and M.J. Dickinson
}

\begin{abstract}
As the care of people with learing discbillty has shifted from large Victorion hospliats to the community, provision for in-patient poychiatic treatment has, in many districts, also moved. Pupose bullt district or supradistrict admission services represent the most common model. An alternative is the use of existing general poychiatilic beds. In this article we describe the first 18 months of the Hillingdon district service where this latter model has been adopted.
\end{abstract}

The last 20 years have seen a significant change in models of psychiatric service for people with learning disability. Until recently the majority of individuals requiring admission went to large hospitals typically situated on the periphery of major towns where there was also provision for residential care. Many of these are now closing, or have closed, with districts developing alternative community facilities.

In North West Thames purpose-built community units serving single districts have appeared and there is at least one supra district service, based in the community, offering psychiatric admission facilities in learning disability from its three surrounding districts, as well as encouraging extra contractual business. An alternative strategy is to use existing adult psychiatry beds.

We would like to describe the first 18 months of the Hillingdon district service where, following agreement with medical, nursing and managerial groups, admission facilities for people with psychiatric illness and learning disability were made available on a general psychiatric ward at the local district general hospital (DGH). The service was to be supported by weekly consultant ward rounds, senior registrar visits and, if necessary, Leavesden Hospital, the large Victorian hospital that historically served Hillingdon along with other north London areas.

\section{The study}

Notes on all admissions to Hillingdon DGH for the psychiatric care of people with learning disability were collected between June 1991 and December 1992, (the first 18 months of this service). Records were taken of age, sex, length of stay, reason for admission, past psychiatric history, level of handicap, diagnosis (DSM-III-R) and treatment, in addition to social factors identified as important in the admission/discharge processes of this group (Dickinson \& Singh. 1991).

\section{Findings}

There were 13 admission episodes during this period, comprising 11 individuals, five men and six women, average age 38 . None of the men but two of the women were married.

The main reason for admission was following overdose/suicidal ideation, ( 3 out of 5 men, 3 out of 6 women), or aggression, ( 2 out of 5 men, 3 out of 6 women). Average length of stay was eight weeks. Two men and one woman were admitted under a section of the Mental Health Act, a third man requiring detention during his admission. All 11 individuals had a past psychiatric history. 
Regarding physical health, two subjects had diabetes (one case complicated by a chronic leg ulcer) and one had a history of hysterectomy and eczema. None of the 11 had a significant physical handicap.

Five individuals came from their own or parental home, three from hostels, and one each from a group home, other hospital, and a nursing home. Six were discharged to the same place, four transferred to Leavesden and one moved from the parents' home to a foster home. All had borderline or mild handicap.

It was difficult to classify the group accurately using DSM-III-R but two of the males seemed to have borderline personality disorder, one paranoid personality disorder, one bipolar disorder, (manic) and one dysthymia. Of the females, two had no axis one diagnosis, one dependent personality disorder (past diagnosis of schizophrenia), one schizophrenia, one obsessive compulsive disorder and one bipolar disorder (manic).

Diagnoses of those transferred to Leavesden were mania (2), paranoid personality disorder, and obsessive compulsive disorder. Six months later only one of these people has been discharged (to a different residence from the place of admission).

Ten of the 11 received medication including eight prescriptions for neuroleptics, six for antidepressants, one for carbamazepine and one for lithium. Apart from community team support, six of the seven subjects discharged directly from Hillingdon were also offered out-patient followup.

\section{Comment}

With profound changes taking place in models of psychiatric care there is no typical service. Hillingdon is a fairly average London district with a population of approximately 230,000 , generating admission rates of about eight a year for front line psychiatric services, similar to that reported by Cooke (1991).

The use of a general psychiatric ward has only recently come about and problems have arisen, particularly those presented by aggressive behaviour. This was further complicated since the acute ward had established back-up at a local locked facility not also available to individuals with learning disability. There was a trend for individuals with major psychiatric illness and deceased parents to become more chronic (the group requiring transfer). Three of these four have now been in hospital for about nine months and are likely to become new long stay.

There are some disadvantages to this type of service. Lack of training and experience in general psychiatric nursing staff make it difficult to undertake behavioural programmes. Occupational therapy designed for the normal intelligence population may not be appropriate. Longer admissions appropriate for some people of lower ability are less likely to be tolerated in an acute DGH ward where an asylum function is lost. No admissions for people with moderate or severe levels of handicap were required but these will occur and it is difficult to imagine them fitting easily on an acute admission ward. Junior medical staff may also feel uncomfortable looking after them.

But the service is local, integrated, readily available and, in using existing facilities, cheap to set up. Service development offers employment of nurses trained in learning disability, patients receiving specialised day care at local facilities close to the hospital while still inpatients, and specialist services visiting the hospital (e.g. psychology, speech therapy). There is proximity to medical and surgical services in addition to 'high-tech' investigations. An association with adult psychiatry may raise the profile of the sub-speciality, in addition to facilitating two way education.

The service may be able to deal with a greater percentage of admissions but, at this stage, its success has depended on back-up. Whether it will eventually be able to cope without the need for occasional transfers to a specialised unit is doubtful but this does not have to be provided by a large Victorian hospital.

\section{References}

Cooke, L. B. (1991) Admissions to mental handicap hospitals. British Medical Journal. 303, 787.

Dickinson, M. J. \& SiNGH, I. (1991) Mental handicap and the new long stay. Psychiatric Bulletin. 16, 334-335.

I. Singh, Consultant, Psychiatry of Mental Handicap, Leavesden Hospital, College Road, Abbots Langley, Herts. WD5 ONU and Hillingdon Hospital, Pield Heath Road, Uxbridge UB8 3NN; M. I. Khalid, Registrar, Psychiatry of Mental Handicap. Leavesden Hospital; and M. J. Dickinson, Senior Registrar, Psychiatry of Mental Handicap, Cell Barnes Hospital, Highfield Road, St Albans ALA ORG 